\title{
La ex Acordada y Belén, una visión de la rehabilitación penitenciaria en la prisión femenina en México (1833-1882)
}

\section{The ex-Acordada and Belén, a View of Rehabilitation in Two Women's Prisons in Mexico (1833-1882)}

\section{Fernanda Sigüenza Vidal}

UNIVERSITÉ DU QUÉBEC À MONTRÉAL, siguenza_vidal.maria_fernanda@courrier.uqam.ca

El objeto de este estudio es el tratamiento carcelario que las presas recibieron en dos cárceles nacionales mexicanas en las que se intentó la reforma penitenciaria, la cárcel de la ex Acordada y la de Belén. Se analizan algunas de las características de las presas, la manera como fueron incluidas en los reglamentos carcelarios y las modificaciones que se hicieron en el departamento de mujeres después de la renovación penitenciaria que pretendía la rehabilitación de aquellas mujeres, especialmente, gracias al trabajo y a su educación.

Palabras Clave: cárcel de la ex Acordada, cárcel de Belén, mujeres presas, reforma penitenciaria mexicana.

This article focuses on the treatment that women inmates received in two federal prisons in Mexico that were sites of attempts to implement prison reform: the ex-Acordada and Belén. The study analyzes key characteristics of the inmates, examines how women prisoners were included in prison regulations in general, and describes the modifications made to the areas set aside for women in those prisons after the implementation of initiatives of prison reform, especially in relation to topics like work and education.

KEYwORDS: ex-Acordada prison, Belén prison, women inmates, prison reform in Mexico.

Fecha de recepción: 27 de marzo de 2017 / Fecha de aceptación: 28 de diciembre de 2017 / Fecha de versión definitiva: 8 de marzo de 2018

\section{INTRODUCCIÓN}

n uno de los patios de la cárcel de Belén había una fuente
que varios consideraron bellamente adornada, quizás por ser
tan llamativa, pronto formó parte de una conocida leyenda:
se contaba que cuando el inmueble sirvió de convento, una monja
se había ahogado en aquella majestuosa fuente. Las demás religiosas 
aseguraban haberla visto deambulando por el edificio, purgando su condena por no haber sido tan creyente como era necesario, motivo por el cual había recibido una muerte tormentosa. ${ }^{1}$ Los reclusos de la cárcel de Belén "contagiados por la superchería, los nerviosos llegaron a creer que habían visto y oído lo que hacía la mujer ahogada durante su peregrinación nocturna de alma en pena". ${ }^{2}$ Para esta investigación no es importante si esta leyenda es verdadera o no, son las reacciones de los presos ante situaciones como éstas las que deben llamar nuestra atención, pues, justamente los acontecimientos que a nuestros ojos pueden parecer más increíbles eran los que afectaban su cotidianidad. Esta leyenda se presenta como un claro ejemplo de lo que siempre se quedaba fuera de los cálculos legislativos y carcelarios, pero que algunas veces resultaba más representativo y cercano para los reos que las disposiciones de las autoridades.

Durante buena parte el siglo XIX, en México se buscó la creación de una penitenciaría, no obstante, la poca estabilidad política y económica del país no la hizo posible, de tal forma que para mitigar los problemas de las cárceles existentes, especialmente, en la Ciudad de México, se intentó una renovación o reforma carcelaria basada en dos pilares principales: la educación y el trabajo. Vale la pena hacer una serie de breves precisiones sobre los términos y el desarrollo de la reforma penitenciaría en México.

En principio, existe una diferencia entre una cárcel y una penitenciaría. Mientras que la primera cumple solamente con una función punitiva de aislamiento, la segunda es uno de los brazos de un sistema penitenciario con el que se busca llevar al recluso por el camino de rehabilitación hasta que se encuentre listo para reintegrarse a la sociedad como uno más de sus miembros productivos. ${ }^{3}$ Este nuevo sistema de punición, el penitenciario, está caracterizado por una serie de elementos, entre los cuales destaca el espacio, es decir, la penitenciaría como el punto determinante para lograr y manejar la

${ }^{1}$ Guillermo Mellado, "Belén por dentro y por fuera”, Criminalia (8) (agosto 1959): 405.

${ }^{2}$ Idem.

${ }^{3}$ Antonio Padilla Arroyo, De Belem a Lecumberri: pensamiento social y penal en el México decimonónico (México: Archivo General de la Nación, 2001), 152. 
rehabilitación de los presos. ${ }^{4}$ En lo que a arquitectura se refiere, el panóptico, propuesta del inglés Jeremy Bentham, fue durante mucho tiempo el diseño considerado más eficaz para el propósito de vigilancia y aislamiento de los reos.

Para que la penitenciaría cumpla con su principal objetivo, la rehabilitación, tiene que convertir al recluso en un individuo disciplinado y trabajador que deje de ser una carga social, de manera que seguir este carácter productivista deviene uno de los principales objetivos de la mayoría de las instituciones penitenciarias. ${ }^{5}$ En México, durante buena parte del siglo XIX se intentó crear una institución penitenciaria moderna y acorde con los preceptos internacionales de la época, sin embargo, las condiciones políticas y económicas del país no permitieron esto hasta el Porfiriato, cuando el anhelo penitenciario logró culminarse con la apertura de la Penitenciaría de Lecumberri en 1900. No obstante, las propuestas y proyectos decimonónicos fueron múltiples y la mayoría de ellos tenían como ejemplos por seguir dos modelos estadounidenses con sistemas de reclusión celular: el Filadelfia y el Auburn.

Ambos sistemas estaban pensados para que el reo, en un mediano o absoluto aislamiento tuviera la oportunidad de reflexionar sobre su delito, llegara al arrepentimiento y a la rehabilitación. El sistema Filadelfia pugnaba por el absoluto aislamiento del recluso, al que se le permitía tener contacto solamente con personas que contribuyeran a moralizarlo en su proceso de rehabilitación; este sistema tuvo una fuerte carga religiosa (protestante) que generó varios debates en el proceso de construcción de una penitenciaría en México. ${ }^{6}$

${ }^{4}$ Nydia Cruz Barrera, La institución penitenciaria, la antropología criminal y el saneamiento social en Puebla en el siglo XIX (México: Instituto Nacional de Ciencias Penales, Procuraduría General de la República, 1994). Los otros elementos propuestos por la autora son la conmutación de la pena de muerte por la de prisión; la proporcionalidad entre la pena y el delito; la introducción de propuestas científicas en torno a la penalidad; y la expectativa en el arrepentimiento y enmienda de los delincuentes.

${ }^{5}$ Dario Melossi y Massimo Pavarini. Cárcel y fábrica: los origenes del sistema penitenciario (siglos XVI-XIX) (México: Editorial Siglo XXI, 2005), 65.

${ }^{6}$ Fernanda Sigüenza Vidal,"'La entrada está en tus manos, la salida en las de Dios'. La religión como medio de rehabilitación de los presos en la cárcel de Belén y la penitenciaría de Lecumberri (1874- 1900)", Revista de Historia de las Prisiones (2) (2015). 
En el sistema Auburn, el aislamiento absoluto solamente era nocturno y se tenía que complementar con días de jornadas de trabajo en los talleres de las cárceles, pero exigiendo a los presos el más absoluto silencio. ${ }^{7}$

Fuera de todas estas reflexiones y propuestas penitenciarias estaba la realidad de un país, específicamente, reflejado en la Ciudad de México, que no pudo consagrar todos estos proyectos hasta finalizado el siglo XIX, pero que durante varios años intentó hacer de las prisiones existentes lugares de rehabilitación para los presos. Justamente en este contexto se encontraban las mujeres presas que aquí se muestran. Dentro de edificios y reglamentos del viejo orden carcelario, pero con un ambiente intelectual y político que todo el tiempo quiere hacer llegar a esas viejas cárceles las novedades de los modernos sistemas penitenciarios. ${ }^{8}$ En la capital del país, existieron dos cárceles nacionales en las que se intentaron implementar estas modificaciones, la cárcel de la ex Acordada y la de Belén. Entre ellas existe un hilo que las une, que es, justamente, el hecho de ser los dos laboratorios en los que se llevaron a cabo varios intentos por lograr una reforma penitenciaria improvisada, pues, carecía de su elemento principal, ese edificio llamado penitenciaría.

El inmueble colonial que había servido de cárcel al Tribunal de la Acordada de 1759 a 1813 reabrió sus puertas desde 1831 hasta 1862 como la Cárcel Nacional de la ex Acordada, para 1862, fue

${ }^{7}$ Sergio García Ramírez, El artículo 18 constitucional: Prisión preventiva, sistema penitenciario, menores infractores (México: Universidad Nacional Autónoma de México, 1967). Padilla, De Belem a Lecumberri. Melossi y Pavarini, Cárcel y fábrica. Posteriormente se incluyó en los debates en México el sistema Croffton, que finalmente fue el utilizado para la Penitenciaría de la Ciudad de México.

${ }^{8}$ El tema de la reforma penitenciaria ha sido ampliamente tratado por muchos historiadores. Véanse Padilla, De Belem a Lecumberri. Antonio Padilla Arroyo, "Pobres y criminales. Beneficencia y reforma penitenciaria en el siglo xIx en México", Secuencia (27) (1993). Sergio García Ramírez, El artículo 18. Elisa Speckman Guerra, Crimen y castigo: legislación penal interpretaciones de la criminalidad y administración de justicia (Ciudad de México, 1872-1910) (México: El Colegio de México, 1999). Graciela Flores Flores, "Cárcel, penitenciaría y reclusorios en dos momentos dentro del proyecto de prisiones en la Ciudad de México (siglos XIX y Xx)", en Crimen y justicia en la historia de México. Nuevas miradas, coord. Salvador Cárdenas Gutiérrez y Elisa Speckman Guerra (México: Suprema Corte de Justicia de la Nación, 2011). 
sucedida por la Cárcel Nacional de Belén, que cerró en 1933. El devenir de Belén estuvo estrechamente marcado por la planificación y el desarrollo de la Penitenciaría de Lecumberri, de manera que desde 1882, fecha de cierre de esta investigación, el proyecto de la Penitenciaría Nacional comenzó a cobrar tal fuerza que la cárcel de Belén pasó a segundo plano en las reflexiones de los penitenciaristas y, a partir de 1900, Belén perdió cada vez más importancia por la inauguración de la moderna penitenciaría.

Sin embargo, sin importar el inmueble del que estemos hablando, tampoco hay que olvidar que se dieron varios casos en los que las reformas planeadas para las cárceles no afectaron la vida de los reos, aunque fueran muy bien ideadas o con intenciones altruistas. Los presos vivían en una realidad que no era completamente abordada por las reformas y en la que casi no eran seguidos los reglamentos de las prisiones. En el departamento de mujeres, como quizá en ningún otro, estas dos condiciones se unían la mayor parte del tiempo, pues, se conjugaban la desobediencia general de los reglamentos que prevaleció en la ex Acordada y en Belén, con normas o costumbres que eran generadas por las propias reclusas para conseguir un día a día mucho menos problemático y con una invisibilidad casi absoluta de las presas en los proyectos penitenciarios reformatorios.

Entre mujeres de diversos orígenes y variados motivos de encarcelamiento, las maneras de vivir dentro de cualquiera de las dos cárceles decimonónicas más importantes en la Ciudad de México fueron muy distintas, a pesar de que todas ellas compartieron el mismo inmueble. La variedad de reas de la cárcel de la ex Acordada y de Belén, que se presentaba a diario, no se parecía del todo a los modelos pensados por las autoridades.

Por otra parte, es indispensable aclarar que en este artículo no se abordará la vida en la cárcel de la ex Acordada, tajantemente dividida de la de Belén, pues, a pesar de que la mudanza a Belén tuvo como objetivo el cambio, la continuidad entre una prisión y la otra es evidente. Esto se debe, entre otras cosas, a que el cambio no se hizo más que por el deterioro en el que se encontraba físicamente el inmueble de la Acordada y Belén apareció como un edificio en mejores condiciones, más amplio y desocupado, que por su origen 
como convento presentaba algunas características arquitectónicas útiles para una cárcel. ${ }^{9}$ Además, se pretende que con el trascurrir de las líneas quede aún más claro que esto se dio, especialmente, en el caso de los departamentos femeninos, aunque los espacios ocupados por las reas tuvieron una distinta distribución en cada cárcel, la vida diaria no se modificó considerablemente con el cambio de un edificio al otro.

\section{LAS MUJERES Y LA CÁRCEL. LAS REAS}

A la cárcel de la ex Acordada, y años más adelante a la de Belén, llegaron mujeres de diferentes estratos sociales, grados de educación, orígenes, complexiones físicas y sentencias; no se puede negar que la gran mayoría vivía en la pobreza, sin embargo, se dieron excepciones. Unas encarceladas por crímenes considerados exclusivos de mujeres, como la prostitución; otras por el clásico robo, o robo con lesiones; también hubo condenadas por asesinatos; y en ocasiones por infanticidio. Para tener una idea, por lo menos, cercana de la manera en que vivían las reas de la Acordada y Belén, es importante tomar en cuenta la cantidad de mujeres que tenían que albergar estos dos edificios, pues, gracias a la comparación entre el espacio y el número de las ocupantes se podrán entender mejor los conflictos y actividades del departamento de mujeres.

El número de reclusas que compartieron estos espacios siempre estuvo muy por debajo de las cifras de los reclusos varones, esta disparidad de ninguna manera significó para las presas el disfrute de un espacio suficiente para todas. En lo que se refiere a la cantidad de mujeres que entraban y salían de la prisión, hay que decir que fueron pocas las que permanecían por mucho tiempo, sin embargo, desde que la Acordada abrió una cárcel especial para mujeres, la acumulación de reclusas siempre se mantuvo o aumentó. Es innegable que en ese dato están implicadas muchas cuestiones que tienen que ver con el desarrollo social de la mujer y con la construcción

${ }^{9}$ AHDF, Ayuntamiento Gobierno del Distrito Federal, Cárceles en General, vol. 499, exp. 393, 1862 . 
social del género femenino, no obstante, para este trabajo resulta más importante observar que el número de presas ascendía continuamente y que, contrario a eso, el departamento de mujeres de cualquiera de las dos prisiones nunca creció espacialmente.

Es importante recordar que la cárcel de la Acordada abrió sus puertas con un departamento femenino entre 1781 y 1782. En los primeros once años, juzgadas todavía por el Real Tribunal de la Acordada, fueron encarceladas 158 mujeres. En 1784, ingresó la primera mujer al nuevo departamento, que posiblemente hasta ese año se terminó de construir completamente. Fue, 1786, el año de mayor cantidad de mujeres presas, 50, número muy elevado para el promedio de 30 mujeres en los demás ańos, no obstante, ninguna de aquellas cifras anunciaba la cantidad de reclusas que se aglomeraría años más tarde. ${ }^{10}$

En la segunda etapa de esta cárcel, es decir, ya en la ex Acordada, iniciada en 1831, el acondicionamiento del inmueble fue menos problemático, pues, en realidad solamente se regresó el edificio a su función original. En los primeros once años de funcionamiento se puede comprobar cómo el número de reas creció considerablemente, comparado con la etapa anterior, además está de más decir que el espacio siguió siendo el mismo. A pesar de que el edificio de la Acordada se retomó como cárcel para mayor comodidad de los recluidos, en cosas tan simples como la comparación entre las 158 internas, que abrieron la historia de la prisión en el departamento femenino, y las 1,379 que transitaron en el onceavo ańo de la segunda apertura, se puede notar que, por lo menos, las reas no gozaban de la comodidad prometida. ${ }^{11}$

Es importante diferenciar entre las cifras dadas por el cálculo de las entradas y las salidas de mujeres de todo un año, como en los ejemplos anteriores, y los números que arrojaban conteos de un solo día, como el de julio de 1862 cuando un visitador de la ex Acordada

${ }^{10}$ Alicia Bazán, "El Real Tribunal de la Acordada y la delincuencia en la Nueva España”, Historia Mexicana (3) (enero-marzo 1964): 337.

${ }^{11}$ Brantz Mayer. México lo que fue y lo que es (México: Fondo de Cultura Económica, 1953), 353. 
dijo haber contado 169 mujeres en la prisión. ${ }^{12}$ Estos números aclaran la diferencia entre la cantidad de mujeres que permanecían en las cárceles y las que iban entrando y saliendo día a día; lo que a su vez habla de que las condenas que normalmente purgaban las mujeres no eran tan largas, pues, la movilidad anual de las presas parece muy constante.

Ya en la cárcel de Belén, el número de reas era mayor que el de la Acordada, pero no crecía disparadamente. Por ejemplo, en 1863 entraron a Belén 2,699 mujeres y salieron 2,430, quedaron en prisión 269 , el 31 de diciembre; ${ }^{13}$ años más tarde, en 1870 , el número de presas bajó hasta oscilar entre 170 y 180, cantidad que volvió a subir en 1873 cuando vivieron en el departamento 211 mujeres. ${ }^{14}$ En promedio, para 1881, entraban diariamente 8 mujeres a la cárcel de Belén, y salían 6 aproximadamente, ocupaban, con normalidad, los dormitorios de la prisión 255 reas cada noche. ${ }^{15}$

Ahora bien, las estadísticas únicamente estaban destinadas a contar el total de los presos, estos números que solamente a veces desagregaban los datos por género, por ello, llama la atención que en 1881, seguramente con el espíritu penitenciario rondando muchas de las acciones en torno a las cárceles, por primera vez apareció la cantidad de niños que habitaban el inmueble en un reporte oficial de las entradas y salidas a la cárcel de Belén, y que casi podemos afirmar, lo hacían en el departamento de mujeres, pues, probablemente acompañaban a sus madres a cumplir sus condenas. Aproximadamente vivieron en Belén 20 niños durante 1881. ${ }^{16}$

En el caso de las presas, se debe sumar la mescolanza entre todos los tipos de criminales debido al deterioro de sus edificios y al hacinamiento en el departamento de mujeres, ya que a pesar de que la 1862

${ }^{12}$ AHDF, Ayuntamiento Gobierno del D.F., Cárceles en general, vol. 499, exp. 393,

${ }^{13}$ Javier Piña y Palacios, "El imperio de Maximiliano y las prisiones de México 1864", Criminalia (8) (agosto 1959), 394.

${ }^{14}$ Padilla, De Belem a Lecumberri, 192. AHDF, Ayuntamiento Gobierno del D.F., Cárceles en general, vol. 500, exp. 509, 1871. 1881.

${ }^{15}$ AHDF, Ayuntamiento Gobierno del D.F., Cárceles en general, vol. 502, exp. 848,

${ }^{16} \mathrm{Idem}$. 
separación entre reos fue uno de los objetivos de la reforma carcelaria, por lo menos, en las cárceles de la ex Acordada y Belén fue siempre un objetivo irrealizable. Día a día se unían en patios, actividades y dormitorios todas las mujeres de la prisión, sin importar el tipo de crimen que hubieran cometido o los años de condena: "Unidas las grandes delincuentes con las víctimas de una imputación calumniosa, prostitutas con las que comienzan a vivir". ${ }^{17}$

En cuanto a los motivos por los que habitaban las cárceles, cabe mencionar que las mujeres casi siempre fueron condenadas por delitos muy similares, nunca tuvieron la gran variedad de infracciones que había en el departamento de varones. Lo más común entre las presas era que se les acusara y condenara por homicidio, robo, rińa o por delitos menores. Los castigos recibidos por aquellas delincuentes, dependen de la época a la que se haga referencia, pues, con la aplicación del Código Penal de 1871 se modificaron algunas cuestiones en torno al castigo, por ejemplo, al departamento de mujeres afectó directamente la abolición de los trabajos forzados fuera de la prisión y de la pena de muerte para el género femenino. ${ }^{18}$ Años antes de la redacción del Código Penal, en el marco de importantes disposiciones para las cárceles, como fueron las de 1833, en la cárcel de la ex Acordada se hizo un recuento de las acusaciones y sentencias de las mujeres presas. De este documento llama la atención que se anote que las mujeres únicamente eran acusadas de homicidio, robo y delitos menores, mientras que en el rubro de sentencias se incluía la pena de muerte, el encierro perpetuo o temporal y exportación. ${ }^{19}$

Para 1842, los tipos de crímenes cometidos por las mujeres, además de haber aumentado en incidencia, se actualizaron y renovaron. A la par de los robos, homicidios y riñas (que a su vez se fueron haciendo mucho más específicos, como riñas y heridas o riñas con porte de armas), se comenzó a culpar a las mujeres de muchos otros

${ }^{17}$ AHDF, Ayuntamiento Gobierno del D.F., Cárceles en general, vol. 499, exp. 393, 1862.

${ }^{18}$ Aarón Hernández López, Código Penal de 1871 (Código de Martínez de Castro), com. Aarón Hernández López, presentación Juan Luis González Alcántara y Carrancá (México: Porrúa, 2000), 50 y 69.

${ }^{19}$ AGN, Justicia, vol. 89, exp. 14, foja 275, 1833. 
delitos como estupros, faltas a la moral, falsificación, adulterio, bigamia, sodomía, incesto y prostitución. ${ }^{20}$ Con los años se fueron sumando nuevos crímenes como el infanticidio, abuso de confianza, compañía en rapto y sospechas de plagio. Estos nuevos delitos no eran muy constantes, normalmente, había una o dos mujeres presas por cometerlos. ${ }^{21}$ Solamente la ebriedad, que pronto se integró a la lista, fue un motivo constante de encarcelamiento para muchas mujeres, aunque no se podría afirmar que ocupara el primer lugar en incidencia, ya que esa mención siempre estuvo entre las riñas y el robo, en sus diferentes y novedosas modalidades.

Como apunta Elisa Speckman en su estudio sobre las mujeres criminales durante el Porfiriato, una de las características de la criminalidad femenina de la época es que los delitos de las mujeres no involucraban el uso de la violencia, muchas veces, fueron delitos contra la moral o en torno a la infancia, es decir, infanticidios o abortos. Además, cabe destacar que la mayor parte de las mujeres condenadas, según las estadísticas oficiales, pertenecían a las clases populares y eran mestizas, sin embargo, como apunta Speckman, es importante considerar la posibilidad de que los datos hayan sido manipulados por las clases altas para apoyar las teorías de la época sobre la relación directa entre la criminalidad y las clases pobres. ${ }^{22}$

Entre todas las presas, algunas se destacaban por poder pagar una vida un poco más cómoda, otras por trabajar verdaderamente dentro de la cárcel, algunas más por representar la autoridad para sus compańeras, pero, sin duda, la situación de las prostitutas llama la atención, pues, a pesar de estar condenadas por comerciar con su cuerpo; dentro de la prisión, donde se supone se debían alejar de la delincuencia, se veían obligadas a seguir haciendo aquello de lo que se les acusaba.

${ }^{20}$ Mayer, México lo que fue y lo que es, 353.

${ }^{21}$ AHDF, Ayuntamiento Gobierno del D.F., Cárceles en general, vol. 500, exp. 509, 1870.

${ }^{22}$ Otras características que compartían las mujeres condenadas durante la época son el analfabetismo, que la mayoría trabajaba fuera de su hogar y que mantenía relaciones de amasiato. Elisa Speckman Guerra, "Las flores del mal. Mujeres criminales en el porfiriato”, Historia Mexicana 47(1) (1997): 190. 
Por ejemplo, en 1878, Luz Méndez, Soledad Vilchis, María Soto y Ángela Romero se quejaron ante el Ayuntamiento del Distrito Federal de que las "mujeres públicas" cuando iban a ser liberadas de la prisión de Belén debían ser llevadas a la Inspección de Sanidad para su reconocimiento y registro. En ese traslado, justamente, encontraban ciertas irregularidades, pues, las recién liberadas tenían que pagar un peso para que las llevaran en coche a la Inspección, ya que de lo contrario tendrían que esperar la remesa que pasaba por varios edificios gubernamentales, que solía tardar mucho tiempo, y había días que no llegaba a la cárcel de Belén. Para conseguir el dinero que se exigía, las liberadas tenían que acceder a la solicitud de servicios sexuales de algunos trabajadores de la cárcel o de algún recluso; hacían, otra vez, aquello que las había llevado a prisión, justo para poder salir libres. Las cuatro mujeres, que denunciaron esa injusticia, declararon que durante varios años una señora pagó el peso de todas las prostitutas que eran puestas en libertad, este beneficio se terminó cuando la mujer obtuvo su libertad. ${ }^{23}$

\section{LA ORGANIZACIÓN EN LOS DEPARTAMENTOS DE MUJERES}

El manejo general en las cárceles femeninas de la ex Acordada y Belén, se rigió por un par de ejes que parecen contrarios, pero que siempre fueron complementarios: la obediencia de algunos dictámenes oficiales y la fuerza de la costumbre, es decir, las reglas que las reclusas iban creando y adecuando diariamente dentro de la prisión. Generalmente, los reglamentos que llegaban a las prisiones eran respetados rigurosamente por un tiempo y, poco a poco, se iban transformando hasta que la ley original se volvía casi irreconocible.

No se puede decir que en los reglamentos existieran muchos artículos exclusivos para las actividades de las reclusas, sin embargo, podemos inferir que algunas indicaciones para el departamento de varones también debían ser aplicadas en el de mujeres, pues, se referían a acciones que necesariamente todos los reos debían realizar, 1878.

${ }^{23}$ AHDF, Ayuntamiento Gobierno del D.F., Cárceles en general, vol. 501, exp. 760, 
como respetar los horarios de actividades; las reglas para la alimentación o los días que podían recibir visitas. En este apartado nos remitiremos al "Reglamento para el gobierno interior económico de las cárceles de esta capital”, publicado el 4 de mayo de 1844, que se aplicó por primera vez en la cárcel de la ex Acordada, pero que, por lo menos en los primeros ańos de Belén, se cumplió en lo que fue posible. Aunque a continuación analizaremos el reglamento, hay que tener en mente que las reas no son el objetivo principal; a pesar de que el departamento de mujeres existía cuando se elaboró, las mujeres son casi ignoradas dentro de la ordenanza. Aquellas reas, lo mismo que las mujeres de la Penitenciaría de Escobedo en Jalisco durante la misma época, representan a las mujeres encarceladas que son "invisibles en el mundo de los fantasmas". ${ }^{24}$

En lo referente al sector femenino, este reglamento únicamente especificó los tipos de talleres propuestos para las mujeres y dictaminó que en los demás rubros se debían aplicar las mismas reglas del departamento de varones. Según esa disposición se pueden deducir algunas reglas que se aplicaron a las presas. Resulta ilustrativo comenzar con los horarios que planearon para la ex Acordada, ya que así podemos tener una idea de las actividades para la corrección de aquellos delincuentes, es decir, para conseguir la rehabilitación a través del encierro.

Las reas debían levantarse a las 5:30 durante el invierno, y a las 5:00 en el verano; a las 8:00 debían iniciar sus labores en los talleres y a las 10:00 en las escuelas. Después de levantarse, según la época del año, hasta las 8:00, debían barrer, limpiar su departamento y desayunar. Si la presa era alimentada por el fondo carcelario el desayuno se servía a las 7:00, en cambio, si su familia llevaba la comida, el horario de sus primeros alimentos era de 6:00 a 8:00, dependía de la hora de recepción de su canasta. En general, los familiares solamente llevaban de comer una vez al día, sin embargo, la recepción de alimentos también se permitía de 16:00 a 17:00. El trabajo y la escuela eran interrumpidos a las 13:00 para que todas comieran,

${ }^{24}$ Jorge Trujillo Bretón, Entre la celda y el muro: rehabilitación social y prácticas carcelarias en la penitenciaría jalisciense "Antonio Escobedo", 1844-1912 (México: El Colegio de Michoacán, 2011), 216. 
después volvían a sus labores y, por la tarde, recibían su cena antes de la oración nocturna. Al terminar los rezos todos se iban a dormir. ${ }^{25}$

Para los días de fiesta se ideó otra organización del tiempo, mucho más sencilla: hombres y mujeres debían asistir a misa, podían ir a las 7:00 o a las 9:00, el resto del día quedaba libre para su aseo personal. ${ }^{26}$

Sin importar su edad o el crimen que hubieran cometido, todas las presas hacían juntas sus actividades diarias, pues, en el reglamento no había una instrucción clara para esto, solamente se dijo que de ser posible no debían convivir las menores de 17 años con las demás: "Los reos menores de diez y siete $[s i c]$ años y que no hayan podido ser admitidos en la casa de corrección, vivirán separados de los demás en cuanto fuera posible, cuidando el inspector de que no traten con los otros, para evitar la corrupción que es consiguiente". ${ }^{27}$ Años más tarde, en 1862, en una visita a la ex Acordada, que puso de manifiesto que el artículo anterior no se tomaba en cuenta dentro de la prisión, se propuso una nueva reglamentación en la que se estipulaba, que en el departamento de mujeres, las menores de 18 años vivirían alejadas de las mayores; las sentenciadas de las detenidas; $y$ las que hubieran cometido delitos menores de las delincuentes mayores. ${ }^{28}$

Una de las separaciones que sí se marcaron fue la de los dormitorios: el de comunes estaba alejado del de distinguidas. En este tema se siguió lo recomendado por el Reglamento de 1844 , en el que se permitió que quienes quisieran una habitación separada de sus compañeros pudieran pagar por ella. Según el documento, las cuotas debían ser entregadas al fondo de la cárcel, pero era bien sabido que la presidenta del departamento también debía obtener ganancias de las habitaciones de las distinguidas, pues, ella acomodaba a las reas en sus dormitorios. En la Acordada, la cantidad por pagar,

${ }^{25}$ El "Reglamento para el gobierno interior económico de las cárceles de esta capital" se consultó en una transcripción hallada en AGN, Gobernación Legajos, legajo 1029, caja 1232, exp. 7, foja 93, año 1860.

${ }^{26}$ AGN, Gobernación Legajos, legajo 1029, caja 1232, exp. 7, foja 93, año 1860.

${ }^{27}$ Idem. 1862.

${ }^{28}$ AHDF, Ayuntamiento Gobierno del D.F., Cárceles en general, vol. 499, exp. 393, 
según el reglamento, debía ser proporcional a las posibilidades de la reclusa, pero tenía que estar entre los cinco y los veinte pesos mensuales; en cambio, en la cárcel de Belén, había que pagar cinco pesos para estar en el dormitorio de primera clase y tres para el de segunda. ${ }^{29}$

El establecimiento de "los presidentes" de cada departamento también quedó estipulado en el documento de 1844, las mujeres también debían tener a su presidenta y el fondo carcelario le pagaría cuatro pesos mensuales. Según el reglamento la manera en que se elegiría era muy sencilla, el inspector de la cárcel escogía a la que tuviera el mejor comportamiento. ${ }^{30}$ Sus funciones correspondían desde cuidar que todas las habitaciones estuvieran bien alumbradas, hasta vigilar que todas sus compañeras se condujeran con orden, decencia y moderación. ${ }^{31}$

La labor de la presidenta es otro buen ejemplo de cómo las indicaciones para el manejo de la cárcel eran amoldadas a la realidad por las propias reclusas. En 1844 se determinó que el trabajo de la presidenta tenía como último fin comunicar al inspector los conflictos del departamento, para que la autoridad los resolviera, sin embargo, se sabe que la presidenta resolvía casi todos los inconvenientes, generalmente, haciendo uso de la fuerza. ${ }^{32}$

\section{LA REFORMA CARCELARIA EN EL DEPARTAMENTO DE MUJERES}

Constantemente se ha hecho referencia a la reforma carcelaria que en México se intentó durante el siglo XIX, pues, aunque las medidas propuestas en el marco de dicha reforma no fueron del todo efectivas, resulta importante rescatarlas, ya que alguna presencia tuvieron en la vida de los reos. Buena parte de su aplicación y éxito dependió de su disposición a obedecer y la manera como los reos adecuaron las reformas a su situación carcelaria. En este apartado se abordarán

${ }^{29}$ AGN, Gobernación Legajos, legajo 1029, caja 1232, exp. 7, foja 93, año 1860. AHDF, Ayuntamiento Gobierno del D.F., Cárceles en general, vol. 500, exp. 521, 1871.

${ }^{30}$ En este sentido, cabe resaltar que, generalmente, las fuentes explican que la presidenta no era la mujer de mejor comportamiento, sino aquella que infundiera más respeto entre sus compañeras, lo que normalmente no ocurría con las bien portadas.

${ }^{31}$ AGN, Gobernación Legajos, legajo 1029, caja 1232, exp. 7, foja 93, año 1860.

32 AGN, Gobernación Legajos, legajo 1029, caja 1232, exp. 7, foja 93, año 1860. 
el trabajo y la educación en los departamentos de mujeres, pues, fueron dos rubros en los que la reforma sí se tomó en cuenta, aunque no se puede decir que eso haya garantizado un verdadero cambio en la cotidianidad femenina.

\section{El trabajo}

De acuerdo con los preceptos penitenciarios de la época, una buena prisión enseñaría a los reclusos nuevas reglas sociales para que reconocieran y respetaran las jerarquías sociales. Una de las propuestas era moralizar a los internos mediante la enseñanza de un oficio honrado, pues, al ponderar las virtudes del trabajo se lograría que los presos reconocieran el camino equivocado que habían tomado. Así, el trabajo se convirtió en una medicina forzada y repetitiva, pero que encarnaba un fundamental "elemento terapéutico de corrección". ${ }^{33}$

A partir de esas ideas, en la ex Acordada y la de Belén intentaron incluir la práctica cotidiana de un oficio como una de las bases de la reclusión y rehabilitación, lo cual, de cierta manera, llegó al sector femenino de ambos inmuebles. Los trabajos que las mujeres pudieron realizar en la ex Acordada y en la cárcel que la subsiguió se reducen a los sectores de preparación de alimentos, limpieza, costura y la educación, aunque esta última se atenderá en el siguiente apartado.

El trabajo en la cocina y en la limpieza siempre funcionó, a diferencia de los demás talleres en los que se confeccionaba y reparaba ropa, aunque hay que resaltar que aquellas labores no estaban consideradas como talleres. Especialmente, el trabajo en la cocina no era una actividad considerada un medio de rehabilitación para una delincuente, no obstante, fue una actividad que verdaderamente funcionó ininterrumpidamente para ocupar el tiempo de muchas

${ }^{33}$ Es importante considerar que el tipo de moralización que se intentaba dar a los reclusos responde totalmente a los valores liberales y cristianos, de manera que el gran objetivo era reconducir a los presos hasta lograr convertirlos en individuos respetuosos de la legalidad, honrados, buenos cristianos, ejemplares padres de familia y, principalmente, personas que comprendieran que solamente podían satisfacer sus necesidades mediante el trabajo asalariado. Pedro Trinidad Fernández, La defensa de la sociedad: cárcel y delincuencia en España (siglos XVIII-XX) (Madrid: Alianza Editorial, 1991). Melossi y Pavarini, Cárcel y fábrica. 
mujeres. Quizá porque era un trabajo que la vida diaria de los presos exigía y por ello no podían parar por más que los materiales ya no sirvieran o fueran muy reducidos. Estas circunstancias se verán más adelante, primero se abordarán las tareas que propusieron las reformas para la rehabilitación carcelaria femenina, incluyendo la limpieza, pues ésta si fue pensada por algunos como una manera para alejar a las mujeres de las transgresiones.

Ya se revisó la manera en que el reglamento de 1844 presentó las labores que debían hacer las mujeres, ahora solamente es importante apuntar que éste estableció, entre otros puntos, que era necesaria una gratificación para las cocineras, atoleras y tortilleras de la cárcel y que en el ramo del trabajo de las mujeres (considerado separadamente de la preparación de alimentos) el artículo 30 ordenó a propósito del establecimiento de talleres:

Los empresarios establecerán también los talleres que crean convenientes en la cárcel de mujeres, y entre tanto podrán destinarse á todas á hilar, tejer, escarmenar y varear algodón, ó á coser ropas propias ó ajenas, escogiendo cada una el que más le acomode de estos ramos ó otros de industria; sin que á ninguna se le permita dejar de ejercitarse en alguna cosa, si no es por motivo de enfermedad calificada por el facultativo, á otro poderoso á juicio de la junta inspectora. ${ }^{34}$

Puede intuirse que este mandato no se cumplió porque más adelante, en el reglamento que se propuso en 1862 como resultado del mal estado en que se encontraba la cárcel de la ex Acordada, el visitador resaltó que para que la estancia en la prisión de verdad fuera correctiva para todas las mujeres, era necesario que en su departamento también hubiera talleres o, por lo menos, que se les destinaran algunas labores en las que pudieran ocupar su tiempo. ${ }^{35}$

Javier Piña y Palacios, uno de los juristas más importantes de México, encontraba las cárceles mexicanas, especialmente la de Belén, como un foco latente de enfermedades y de perversiones. Según

${ }^{34}$ AGN, Gobernación Legajos, legajo 1029, caja 1232, exp. 7, foja 93, año 1860.

${ }^{35}$ AHDF, Ayuntamiento Gobierno del D.F., Cárceles en general, vol. 499, exp. 393, 1862. 
él, esta situación podía tener una solución, en el departamento de mujeres, si se obligaba a todas las reas a que lavaran sus "ropas exteriores", ya que esa actividad cumpliría una doble función: la distracción de las reas y la prevención de enfermedades. Persiguiendo el mismo fin, planeó el restablecimiento de la lavandería en el departamento de mujeres, con ella se daría trabajo remunerado a buena cantidad de reclusas y la cárcel de Belén se volvería un lugar mucho más higiénico. ${ }^{36}$

El taller de lavandería sí funcionó en el departamento de mujeres, pero los resultados nunca fueron los esperados, los problemas con las reas eran recurrentes, pues, no entregaban la ropa a tiempo y extraviaban algunas prendas. Aprovechando eso, un grupo de hombres, "los pederastas y afeminados", encabezados por los reos Florindo y Margarito crearon su propio taller de lavandería y planchaduría, que muy pronto adquirió muchos más clientes que el taller de lavanderas del departamento de mujeres, ya que "los hombres-lavanderas", como les llamaban, no robaban la ropa, cobraban muy poco y hacían su trabajo esmerada y puntualmente, tanto que en ocasiones el alcaide de la prisión permitía que les llevaran ropa de fuera para que la lavaran y plancharan. ${ }^{37}$

La otra fuente de empleo, que a veces funcionó en la Acordada y en Belén, fueron los talleres que se creaban cada vez que llegaba un nuevo impulso para aplicar las reformas carcelarias. Por ejemplo, en 1831, cuando la Acordada se convirtió en Cárcel Nacional se formaron 5 talleres para mujeres: de hiladoras de algodón, costureras, lavanderas, telares de paños de algodón, y de tejedoras de puntas y encajes. ${ }^{38}$ En 1833, respondiendo a lo dictado por el "Reglamento aprobado por el Supremo Gobierno para el establecimiento y gobierno de talleres de artes y oficios en la Cárcel Nacional", se reportó que había un total de 65 mujeres trabajando en los talleres de la prisión y 30 más "dispuestas a coser ropa de munición de lienzo". ${ }^{39}$

\footnotetext{
${ }^{36}$ Javier Pińa y Palacios, “Las cárceles en 1875”, Criminalia (8) (agosto 1959): 483.

${ }^{37}$ Mellado, "Belén por dentro y por fuera", 412.

${ }^{38}$ AGN, Justicia, vol. 89, exp. 32, foja 266, 1831.

${ }^{39}$ AGN, Justicia, vol. 147, exp. 11, foja 69, 1833.
} 
Para que fuera posible el funcionamiento de la mayoría de estos talleres, al igual que los del departamento de varones, se necesitaban algunos materiales y máquinas o, por lo menos, así lo consideró Valentín Gómez Farías, vicepresidente de México en 1833, quien mandó que se llevaran a la Cárcel Nacional telares y tornos "para que los presos tengan una recuperación honesta y mejore su moralidad". ${ }^{40}$ De esa donación al departamento de mujeres, únicamente llegaron dos tornos grandes y dos chicos, gracias a que el Ayuntamiento de la Ciudad de México intervino ante el director de la prisión, pues, todos los instrumentos se habían dejado en el departamento de hombres. ${ }^{41}$

Después de la mudanza de aquellas máquinas a la ex Acordada quedaron en el Hospicio de los Pobres diez telares estadounidenses que hubieran sido muy útiles a las reclusas, pero no se trasladaron porque éstas no tenían la instrucción necesaria para manejarlos. Ante el inconveniente de que las mujeres solamente supieran manejar los tornos del país, se tomaron 3 pesos y 6 reales de los fondos de la cárcel para comprar 6 tornos nacionales, ya que se esperaba que con eso las reclusas tuvieran la posibilidad de incrementar su producción. ${ }^{42}$ Los tornos que se adquirieron eran utilizados por las trabajadoras que se ocupaban de escarmenar e hilar algodón, pues, las restantes se dedicaban a hacer camisas de munición o costuras a particulares. Durante algunos años las reas se dedicaron a la confección de camisas para los soldados, de camisas finas para hombres, de fundas de colchones y de naguas. ${ }^{43}$

En la cárcel de Belén, en fechas cercanas a 1873, junto a los trabajos de costura y bordado, ya estaban las mujeres que hacían las labores administrativas del departamento. De las 211 mujeres que en ese momento vivían en el inmueble, sólo 27 se integraron a los talleres de costura y bordado, las demás participaban en la cocina o la atolería, y unas cuantas eran parte de la dirección del departamento, como presidentas, celadoras, voceras, encargadas de la limpieza y

\footnotetext{
${ }^{40}$ AGN, Justicia, vol. 147, exp. 24, foja 215-218, 1833.

${ }^{41}$ AGN, Justicia, vol. 147, exp. 24, foja 223, 1833.

${ }^{42}$ AGN, Justicia, vol. 147, exp. 24, foja 236 y 260, 1833.

${ }^{43}$ AGN, Justicia, vol. 147, exp. 24, foja 232, 253, 265 y 267, 1833.
} 
una como registrona. Las presas que no realizaban ninguna de esas actividades decían que asistían a la escuela. ${ }^{44}$

Es momento de mencionar la actividad a la que se sumaba la mayor cantidad de reclusas, la preparación de alimentos. Tanto en la ex Acordada como en Belén existieron tres espacios relacionados con la elaboración de la comida para la prisión: la cocina, la atolería y un cuarto de tortilleras. ${ }^{45}$ Las mujeres participaron en estas tres actividades desde que la Acordada era una cárcel virreinal, entonces su trabajo era hacer tortillas, atole y guisar la carne con habas que comúnmente daban a todos los reclusos, sin embargo, hubo una diferencia entre las cocineras de aquella época y las que después sirvieron en las cárceles nacionales: las primeras cumplían con su trabajo sin recibir ningún tipo de gratificación, y se intentó remunerar a las segundas. ${ }^{46}$ En la ex Acordada, cada una de las 43 reclusas que servían en la cocina, a pesar de que ese trabajo era parte de su sentencia, recibía un real cada semana como pago. ${ }^{47}$

Es conveniente remarcar que la cocina, la atolería y la tortillería, es decir, los lugares de mayor afluencia de mujeres, eran los más dañados de las dos prisiones y donde los visitadores carcelarios ponían más atención. De hecho, en ocasiones, eran los únicos espacios del departamento de mujeres a los que se daba importancia. En la ex Acordada, en 1846, el piso de la cocina estaba totalmente desenlosado y con muchos hoyos, además, las cocineras no contaban con las hornillas necesarias y al alcaide se le ocurrió formar unas provisionales, pero eran muy incómodas y las reclusas podían sufrir alguna lesión; asimismo, el tejado de toda la cocina estaba destruido, esto ocasionaba que en época de lluvias las cocineras y la comida se mojaran. ${ }^{48}$

La atolería de la Acordada tampoco era el lugar más adecuado para trabajar, pues, había una mezcla de diferentes líquidos enchar-

${ }^{44}$ Padilla, De Belem a Lecumberri, 192.

${ }^{45}$ En la cárcel de Belén también hubo una panadería, pero solamente trabajaron los hombres. 1799 .

${ }^{46}$ AHDF, Ayuntamiento Gobierno del D.F., Cárceles en general, vol. 495, exp. 22,

${ }^{47}$ AGN, Justicia, vol. 147, exp. 16, foja 130, 1833.

${ }^{48}$ AGN, Justicia, vol. 333, exp. 30, foja 147, 1846. 
cados por todo el piso, ya que las atoleras los transportaban en pequeños cubos que no estaban en buen estado y derramaban el contenido por todo el camino. En octubre de 1855 se ideó llevar un tubo desde el tinaco que estaba en la cocina hasta la atolería, y poner una llave para que solamente saliera el agua necesaria, sin embargo, esto nunca se concretó y las atoleras nunca gozaron del privilegio de dejar de acarrear agua diariamente. ${ }^{49}$

Lo mismo ocurrió con las ventanas que se pondrían en el cuarto destinado a hacer tortillas en la cárcel de Belén. Las trabajadoras se sofocaban por la gran cantidad de humo que se encerraba, debido a que todo el tiempo se quemaba leńa para que el comal estuviera caliente, mediante sistemas de ventilación se pretendía que sus labores fueran mucho más ágiles, sin embargo, el proyecto no se realizó. ${ }^{50}$

$\mathrm{Al}$ mismo tiempo, en las cocinas, atolerías y tortillerías, el estado de los materiales para trabajar era muy malo. Ya se mencionó sobre los baldes de las atoleras para cargar agua en la Acordada, ahora se debe resaltar que en Belén las cosas no mejoraron, la cocina no tenía los enseres necesarios para la elaboración de comida diaria; hasta 1875 las autoridades se dieron cuenta de que ya era indispensable conseguir un perol y dos ollas para que las presas pudieran preparar los alimentos eficazmente. ${ }^{51}$

El trabajo de las mujeres cocineras era tan importante para toda la prisión que no se podía interrumpir, ni siquiera para que las reas se encargaran de su arreglo personal. Por eso en 1881, en medio del último gran impulso por convertir la cárcel de Belén en una penitenciaría, se autorizaron 21.75 pesos para comprar 2 piezas de manta blanca y 8 de estampada, con esa tela se uniformaría a las cocineras de la prisión. ${ }^{52}$ Desde una de las visitas de 1870 se hizo mucho hincapié en que había muchas mujeres que por la sobrecarga 1855

${ }^{49}$ AHDF, Ayuntamiento Gobierno del D.F., Cárceles en general, vol. 498, exp. 346,

${ }^{50}$ AHDF, Ayuntamiento Gobierno del D.F., Cárceles en general, vol. 500, exp. 456, 1868.

${ }^{51}$ AHDF, Ayuntamiento Gobierno del D.F., Cárceles en general, vol. 501, exp. 668, 1875. 1881.

${ }^{5}$ AHDF, Ayuntamiento Gobierno del D.F., Cárceles en general, vol. 502, exp. 817, 
de trabajo (como el de las cocineras) no tenían oportunidad de bañarse y lavar su ropa, además, consideraron que resolver ese problema era parte de la labor de la sociedad completa: "La sociedad y sus autoridades y funcionarios deben guardar todas las consideraciones posibles a la muger $[s i c]$, aunque sea criminal".${ }^{53}$ Posiblemente, el uniforme nunca llegó a las reclusas, pero las telas con las que se vestirían las mujeres, que verdaderamente trabajaban dentro la prisión, sí fueron compradas.

Sin embargo, las consideraciones a las cocineras tampoco eran demasiadas, por lo menos en la cárcel de la Acordada, pues, a diferencia de sus demás compañeras trabajadoras, las cocineras, atoleras y tortilleras no eran libres de negociar con el fruto de su trabajo, pues, las autoridades prohibieron terminantemente que las cocineras se apropiaran de la comida que sobraba de la alimentación a todos los reos. Sin embargo, sí se dictaminó que de los fondos de la prisión se pagaría su alimentación y, en 1843, se presentó la propuesta de comprarles uniformes. ${ }^{54}$

Hasta aquí, las labores que exigían los reglamentos para la rehabilitación de las mujeres recluidas; ahora hay que reconocer que aparte de éstas, había algunas actividades con las que pocas mujeres, solamente aquellas que tenían una serie de privilegios (introducir mercancías o tener algunos permisos de las autoridades), ganaban dinero sin preocuparse por su rehabilitación.

Este fue el caso de la presidenta del departamento de mujeres en la cárcel de la Acordada, Lucía Chavira, quien a pesar de hacer que sus compańeras guardaran orden y compostura, ganaba un poco de dinero vendiendo entre las internas algunos utensilios personales y en ocasiones comestibles, además comerciaba almuerzos en los Juzgados de Letras. Una de sus compañeras se quejó por el privilegio que tenía esa mujer, pues, argumentaba que además del lucro no 1870

${ }^{53}$ AHDF, Ayuntamiento Gobierno del D.F., Cárceles en general, vol. 500, exp. 509,

${ }^{54}$ Padilla, De Belem a Lecumberri, 168. En el caso de los productos elaborados en los talleres, los artesanos podían venderlos a quien mejor les pareciera, aunque evidentemente lo que más les convenía era permitir que las autoridades carcelarias fueran quienes negociaran con los compradores externos, pues ellos no tenían la posibilidad por estar encerrados. 
permitido, la rea podía salir tranquilamente de la cárcel de mujeres para vender sus productos en las oficinas de los jueces. ${ }^{55}$

Como se ha visto, algunos de los trabajos destinados a las mujeres sí fueron desempeñados continuamente, pero, también ya se mostró que, otros tardaban mucho en comenzar y después solamente operaban por unos meses. Más allá de la importancia de la descripción de la vida laboral cotidiana, vale la pena hacer un par de reflexiones al respecto. Primero, resaltar que si bien las mujeres formaron parte de la reforma penitenciaria, su participación siempre fue condicionada al desarrollo de las medidas en el departamento de hombres, como muestra tenemos el retraso en el establecimiento de los talleres en el sector femenino de las cárceles. En segundo lugar hay que tomar en cuenta el tipo de talleres que se instalaron, ya que todos comparten un rasgo: aunque el propósito de los talleres carcelarios era formar en un oficio a los presos, para las reas los talleres significaron seguir desarrollando las actividades que se consideraban femeninas durante la época, como lavar, coser y cocinar. De manera que después de detallar lo que se consideró como trabajo para las mujeres presas en la ex Acordada y Belén es posible afirmar que el trabajo femenino dentro de la rehabilitación penitenciaria decimonónica significó la reafirmación del rol de las mujeres en la sociedad del siglo XIX. ${ }^{56}$

Ahora bien, la escuela, el otro espacio de rehabilitación, pasó por una situación muy similar, con la diferencia de que la tardanza para iniciar las clases fue mucho más larga que en el caso de los talleres. 1837.

${ }^{55}$ AHDF, Ayuntamiento Gobierno del D.F., Cárceles en general, vol. 497, exp. 172,

${ }^{56}$ Esta misma situación de reforzamiento de los roles de género mediante los sistemas penitenciarios es una constante que ya han hecho patente en otras prisiones femeninas del xIX y principios del xx estudiosos como Jorge Trujillo para la Penitenciaría de Escobedo en Jalisco y Mariana Marín para la de Puebla, así como Elena Azaola y Cristina Yacamán para el sistema penitenciario mexicano de finales del siglo xx. Trujillo, Entre la celda y el muro. Mariana Marín Ibarra, "Espacios de reclusión femenina en la ciudad de Puebla (1862-1867)", Revista de Historia de las Prisiones (2) (2015). Elena Azaola y Cristina Yacamán, Las mujeres olvidadas. Un estudio sobre la situación actual de las cárceles de mujeres en la República Mexicana (México: El Colegio de México, Comisión Nacional de Derechos Humanos, 1996). 


\section{LA EDUCACIÓN}

En el siglo xIx el analfabetismo de la población mexicana era muy elevado, especialmente entre los integrantes de los estratos sociales más bajos, de los que comúnmente se surtían las cárceles. Sin embargo, cuando en los preceptos de la reforma carcelaria se incluyó la educación a los reos, no fue para volver a México un país de lectores, sino como un medio para alejarlos de los vicios y delitos.

Para los reformistas la mejor manera de llevar a los reos hacia su rehabilitación era apartándolos del ocio e inculcando en ellos moralidad, por eso en la instrucción diaria se debían incluir clases en las que los presos aprendieran a leer y a escribir (así, la cárcel les brindaría un sano conocimiento al mismo tiempo que los alejaba del ocio) y también lecciones de moralidad, dirigidas a formar buenos ciudadanos. Generalmente, las clases de moral eran dadas por sacerdotes católicos que más que hablar de las cualidades de un buen ciudadano, intentaban encaminar a todos los presos en su dogma. La corrección de la moral por medio de lecciones tuvo gran empuje en las prisiones, por lo menos, en los primeros años de la reforma carcelaria, la ex Acordada da el ejemplo, donde primero se enseñaron las lecciones de moral y religión en vez de las primeras letras o cualquier otro conocimiento útil para los reclusos. ${ }^{57}$

El caso de las escuelas para mujeres es interesante, pues, su establecimiento, tanto en la Acordada como en Belén, costó mucho más trabajo que los talleres. El retraso se explica en el hecho de que siempre se siguió el formato de la escuela de varones y, por ello, había que esperar a que diera buenos frutos para intentar repetir la fórmula en el departamento de mujeres. Uno de los ejemplos de este procedimiento se puede tomar de la ex Acordada, en 1841, cuando la Compañía Lancasteriana propuso volver la cárcel un lugar "de costumbres, instrucción primaria y religiosa" en vez de una escuela de vicios; la herramienta para obtener aquel resultado era una escuela dominical de primeras letras en el departamento de hombres,

${ }^{57}$ Un ejemplo de esto es el Reglamento de 1844 que estipuló que todos los reos debían recibir, por lo menos, media hora diaria de lección de religión y moral. AGN, Gobernación Legajos, legajo 1029, caja 1232, exp. 7, foja 93, año 1860. 
además desde que la escuela comenzó a funcionar se pensó que pronto sería posible basarse en aquella experiencia para abrir una escuela de mujeres. ${ }^{58}$ En este caso, la espera fructificó, pues, un año y dos meses después, ya estaba instalada la escuela de mujeres. Las mujeres de la Junta de Señoras Socias de la Compañía Lancasteriana contrataron a una profesora para que diera clases a las reclusas todos los días de 7:00 a 10:00 de la mañana. ${ }^{59}$

Aunque aquél no fue el primer intento de señoras de buenas familias para instruir a sus congéneres recluidas. Desde 1841, algunas presas tenían la posibilidad de recibir algunas enseñanzas sobre la lectura y doctrina cristiana, las maestras eran las mujeres distinguidas de la Ciudad de México. ${ }^{60}$ Este proyecto funcionó, sin embargo, no se le puede considerar como una escuela para el departamento de mujeres, pues, no estaba destinado a todas las reclusas.

No sabemos con exactitud cuánto duró la profesora pagada por las Socias de la Compañía Lancasteriana, pues, las noticias de la educación en el departamento de mujeres se vuelven a activar hasta los primeros años de la cárcel de Belén y con reportes que muestran que aquella prisión no representaba la mejor imagen como lugar donde se pretendía educar a los reclusos para que a su salida fueran hombres, mujeres y jóvenes útiles y respetuosos de los demás integrantes de la sociedad. En 1864, toda la instrucción moral que recibían los presos era el sermón que el sacerdote decía en las misas de los días de fiesta y las pláticas que las socias de las Conferencias de San Vicente de Paul daban algunas veces dentro del inmueble. ${ }^{61}$

En lo que se refiere a los primeros intentos por llevar la instrucción a las presas de la ex Acordada y Belén, cabe apuntalar una cuestión que se hizo evidente en la época, el hecho de que aquellas personas que se encargaron de la moralización de las reas eran las 1841.

${ }^{58}$ AHDF, Ayuntamiento Gobierno del D.F., Cárceles en general, vol. 497, exp. 190,

${ }^{59}$ AHDF, Ayuntamiento Gobierno del D.F., Cárceles en general, vol. 497, exp. 205, 1842.

${ }^{60}$ Madame Calderón de la Barca, La vida en México durante una residencia de dos años en ese país (México: Editorial Porrúa, 2006), 389.

${ }^{61}$ Padilla, De Belem a Lecumberri, 221. 
mujeres de buenas familias de la ciudad; las que participan en una sociedad católica; o aquellas que pertenecían al pequeño grupo de las mujeres letradas. Lo que se quiere resaltar es que la educación moral de las presas, más allá de estar basada en el catolicismo o no, tiene como figuras de autoridad a otras mujeres que sí cumplen con sus funciones familiares, religiosas y sociales, a diferencia de las presas que justamente están en prisión por sus transgresiones legales, que en el fondo son transgresiones sociales, pues, "la transgresión social es un componente básico de la falta considerada como delictiva". ${ }^{62}$

Una verdadera escuela de mujeres en la cárcel de Belén llegó con la década de 1870, cuando se reportó que asistían a la escuela de la prisión 43 mujeres a clases de silabario, 9 al repaso del libro de $3^{\circ}$ de niños, 4 al de $2^{\circ}, 4$ a clases de escritura y una a aritmética. Es importante resaltar que la cantidad de mujeres que asistían a la escuela difería de las cifras de los departamentos de hombres y de jóvenes, por ejemplo, en las clases de gramática castellana no había mujeres, sin embargo, el grupo del departamento femenino era el más grande en la lección de silabario. ${ }^{63}$ Ciertamente, en la diferencia entre la asistencia a determinadas materias en el departamento de hombres y en el de mujeres, hay elementos que hablan de la divergencia en la instrucción que afuera tenían hombres y mujeres, sin embargo, profundizar en ese tema no es parte de los objetivos de esta investigación.

Volviendo al tema de las escuelas femeninas en Belén, no se puede obviar que las estudiantes de todas las clases necesitaban de varios utensilios que eran pagados con los fondos de la prisión. Pronto creció la popularidad de la escuela, cada vez eran más las asistentes y se necesitaron muchos más artículos escolares. En mayo de 1872 se elaboró un nuevo presupuesto para los materiales de la Escuela de Mujeres de Belén en el que se autorizaron 572.24 pesos para comprar materiales necesarios para la enseñanza. ${ }^{64} \mathrm{La}$ escuela de las pre-

${ }^{62}$ Elisa Speckman, "Las flores del mal", 193.

${ }^{63}$ AHDF, Ayuntamiento Gobierno del D.F., Cárceles en general, vol. 500, exp. 521, 1871

${ }^{64}$ AHDF, Ayuntamiento Gobierno del D.F., Cárceles en general, vol. 500, exp. 573, 
sas se resurtió con tinteros, pizarrones, burros para pizarrones, algunos ejemplares de libros de lectura lancasteriana, libros manuscritos, libros Amigo de niños, reglas de madera, gises, tinta y una buena carga de papeles blancos y con líneas. ${ }^{65}$

Todos estos enseres eran necesarios para que 152 reas fueran diariamente a la escuela, por lo menos hasta 1873, cuando se destituyó a la profesora porque las reclusas no le tenían respeto, ya que "la mujer era de un carácter muy blando", algo incompatible con un trabajo en el que tenía contacto directo con un "grupo de delincuentes". ${ }^{66}$ Las reas necesitaban de una maestra como María "La Chiquita” Villa, una prostituta que estuvo encarcelada en la Cárcel de Belén y cuyo caso fue muy famoso en la prensa y entre las presas, pues, asesinó a una de sus colegas por haberle robado a su amante. Esta presa conocía la manera de ser de las reclusas por su experiencia de vida y su contacto diario con ellas, lo que le dio estrategias muy eficientes para mantener el orden y la disciplina entre sus compañeras, por tal motivo formó una escuela de mucha calidad. Enseñó a sus compañeras a leer, a escribir y algunas manualidades que ella conocía, poco tardó en reactivar la escuela de mujeres en la cárcel de Belén. Su labor llamó tanto la atención que un día se realizó una visita especial, gracias a aquella inspección, Guillermo de Landa y Escandón, regente de la Ciudad de México, prometió máquinas de coser para las reclusas y abogar por ella ante el presidente para que le otorgara la libertad, aunque faltaran cuatro años de condena. Las dos promesas fueron cumplidas y María Villa salió libre dejando algunas enseñanzas a sus compañeras, seis máquinas de coser y algunas telas que también obsequió Landa. ${ }^{67}$

Varios intentos se hicieron para que la compostura moral llegara a los reos, generalmente, además de las escuelas, o mejor dicho, cuando éstas dejaban de funcionar por algún motivo, se apelaba a la lectura como fuente de corrección. Por ello se pensó en una biblioteca para la Cárcel Nacional de Belén, pero ese método no parecía 1872.

${ }^{65}$ AHDF, Ayuntamiento Gobierno del D.F., Cárceles en general, vol. 500, exp. 573,

${ }^{66}$ Padilla, De Belem a Lecumberri, 192.

${ }^{67}$ Mellado, "Belén por dentro y por fuera", 442- 443. 
suficiente, era necesario idear una manera de acercar a los reos a la lectura y el resultado fue la formación de los presos por grupos para que alguien les leyera en voz alta textos que ayudarían a consolidar su buena moral. ${ }^{68}$ Pronto la idea de la biblioteca se desvaneció, pues, se dieron cuenta de que los libros duraban muy poco, pues, tomaban como pasatiempo deshojarlos, pero la tenacidad de la autoridades no se detuvo ante aquella actitud y mandaron pedir una colección de mapas alfabéticos, para que fuera más difícil destruirlos y así durara un poco más aquella "fuente de conocimiento y de moralidad". ${ }^{69}$

Ahora bien, antes de finalizar el tema es importante remarcar que, como ya se ha presentado, las mujeres estuvieron inmersas en los ideales de corrección del delincuente por medio de la educación, en aquel intento de educarlas para que ocuparan su tiempo en algo útil, como el aprendizaje de la lectura y la escritura, y no en perfeccionar sus vicios y delitos; también recibieron instrucción para que su moral se incrementara gracias a las lecciones impartidas dentro de la prisión; pero en su caso específico, la educación tenía una tercera vertiente: las reclusas debían aprender a ser buenas mujeres, es decir, en la cárcel se les debían enseñar los valores propios de una mujer y cómo ponerlos en práctica: "Educar a la muger [sic], hacerle comprender su santa misión en la tierra, levantar en ella los sentimientos de ternura y los afectos dulcísimos del corazón, deben ser el tema constante e invariable que sirvan de base al Gobierno de la prisión de mujeres $[\mathrm{sic}]]^{\prime}{ }^{70}$

Hasta aquí las muestras de cómo dos de los pilares de la reforma carcelaria se introdujeron en el departamento de mujeres, con los que se intentó encaminar el proyecto penitenciario mexicano. En la ex Acordada y en Belén los ensayos fueron constantes, pero el trabajo y la educación poco recurrentes, debido a que la situación de

${ }^{68}$ AHDF, Ayuntamiento Gobierno del D.F., Cárceles en general, vol. 501, exp. 691 y 770,1872 y 1878 .

${ }^{69}$ AHDF, Ayuntamiento Gobierno del D.F., Cárceles en general, vol. 502, exp. 791, 1880 .

${ }^{70}$ AHDF, Ayuntamiento Gobierno del D.F., Cárceles en general, vol. 501, exp. 770, 1878 . 
hacinamiento; los desperfectos de los inmuebles; la restricción de los recursos; la disposición de las reclusas; y la corrupción de los encargados de las cárceles echaron abajo cada una de las propuestas que se hicieron para poner a funcionar talleres y escuelas, sin importar si en la mira de los proyectos estaba mejorar la vida diaria de las reclusas.

\section{ReFLEXIONES FINALES}

La reforma penitenciaria, en el departamento de mujeres de las cárceles nacionales mexicanas de mediados del siglo XIX, se rigió bajo los preceptos del penitenciarismo de la época, sin embargo, también tuvo algunas particularidades dictadas por la concepción que se tenía de las presas y por las condiciones del departamento de mujeres.

En principio cabe resaltar que la transformación traída por la renovación penitenciaria no fue mucha y que esto no quedó estrictamente restringido al área femenina de la cárcel. Sin embargo, los elementos que caracterizaron a este proceso de transformación carcelaria en México sí se aplicaron en los departamentos de mujeres de la ex Acordada y Belén, es decir, el trabajo y la educación.

En lo que se refiere al trabajo, como se mencionó, el establecimiento de los talleres fue problemático y muchas veces difícil de llevar a cabo, sin embargo, llama la atención en este tema que las labores que realizaban las presas no eran oficios, sino actividades consideradas femeninas, como la elaboración de comida o la limpie$\mathrm{za}$, que no siempre fueron consideradas como rehabilitatorias por los penitenciaristas. Ahora bien, si reflexionamos sobre el tema de la educación ocurre una cosa muy parecida, pues, la instrucción que se relacionaba teóricamente con la reintegración social era la de las primeras letras y materias relacionadas con la obtención del conocimiento, no obstante, en este par de cárceles, incluso durante la renovación penitenciaria, las lecciones más recurrentes y con mayor continuidad fueron aquellas que se relacionaban con la moralización. Lo que en el caso de las mujeres se hacía mucho más evidente, pues, como ya se señaló, se creía que la misión de la rehabilitación carcelaria femenina tenía que ver con una rehabilitación social que, 
al mismo tiempo, inculcara en la mujer valores considerados femeninos como "la ternura y los afectos dulcísimos del corazón". ${ }^{71}$

Foucault considera que el gran éxito de la prisión está basado en que representa una continuidad, nunca una ruptura, con lo que ocurre en el exterior de sus muros, en la cotidianidad social, pero que al mismo tiempo encarna una diferencia entre las personas que viven lo cotidiano en el exterior y los que están en el interior porque cometieron una falta. ${ }^{72}$ En este sentido, los departamentos femeninos de las cárceles de la ex Acordada y Belén, a pesar de todas las fallas que comentamos, a pesar de hacer intentos poco eficientes por implantar un verdadero régimen penitenciario y aunque no cumplieran con su cometido rehabilitatorio, fueron prisiones exitosas, pues, mediante sus talleres lograron que las presas replicaran todas aquellas actividades que normalmente hacían en el exterior, pero al mantenerlas en el encierro, bajo un supuesto régimen de rehabilitación social y con las condiciones de vida que ya comentamos, crearon un claro contraste entre esas mujeres transgresoras y aquellas que vivían en libertad y seguían el patrón de conducta establecido.

\section{Archivos}

(AGN) Archivo General de la Nación

(AHDF) Archivo Histórico del Distrito Federal "Carlos de Sigüenza y Góngora"

\section{BibLIOGRAFÍA}

Azaola, Elena y Cristina Yacamán. Las mujeres olvidadas. Un estudio sobre la situación actual de las cárceles de mujeres en la República Mexicana. México: El Colegio de México, Comisión Nacional de Derechos Humanos, 1996. 1878.

${ }^{71}$ AHDF, Ayuntamiento Gobierno del D.F., Cárceles en general, vol. 501, exp. 770,

${ }^{72}$ Michel Foucault, La verdad y las formas juridicas (Barcelona: Editorial Gedisa, 1996), 128-129. 
BAzÁN, Alicia. "El Real Tribunal de la Acordada y la delincuencia en la Nueva España”. Historia Mexicana (3) (enero-marzo 1964). Calderón De La Barca, Madame. La vida en México durante una residencia de dos años en ese pais. México: Editorial Porrúa, 2006. Cruz Barrera, Nydia. La institución penitenciaria, la antropología criminal y el saneamiento social en Puebla en el siglo XIX. México: Instituto Nacional de Ciencias Penales, Procuraduría General de la República, 1994.

Flores Flores, Graciela. "Cárcel, penitenciaría y reclusorios en dos momentos dentro del proyecto de prisiones en la Ciudad de México (siglos XIX y xx)". En Crimen y justicia en la historia de México. Nuevas miradas, coord. Salvador Cárdenas Gutiérrez y Elisa Speckman Guerra. México: Suprema Corte de Justicia de la Nación, 2011.

Foucault, Michel. Vigilar y castigar. México: Editorial Siglo XXI, 2012.

. La verdady las formas jurídicas. Barcelona: Editorial Gedisa, 1996.

García Ramírez, Sergio. El articulo 18 constitucional: Prisión preventiva, sistema penitenciario, menores infractores. México: Universidad Nacional Autónoma de México, 1967.

Hernández López, Aarón. Código Penal de 1871 (Código de Martínez de Castro), com. Aarón Hernández López, presentación Juan Luis González Alcántara y Carrancá. México: Porrúa, 2000.

Marín Ibarra, Mariana. "Espacios de reclusión femenina en la ciudad de Puebla (1862-1867)". Revista de Historia de las Prisiones (2) (2015).

Mayer, Brantz. México lo que fue y lo que es. México: Fondo de Cultura Económica, 1953.

Mellado, Guillermo. "Belén por dentro y por fuera". Criminalia (8) (agosto 1959).

Melossi, Dario y Massimo Pavarini. Cárcel y fábrica: los origenes del sistema penitenciario (siglos XVI-XIX). México: Editorial Siglo XXI, 2005.

Padilla Arroyo, Antonio. De Belem a Lecumberri: pensamiento so- 
cialy penal en el México decimonónico. México: Archivo General de la Nación, 2001.

. "Control social e instituciones de reclusión. El caso de la penitenciaría de Jalisco en el Porfiriato". Relaciones Estudios de Historia y Sociedad XxII(88) (otoño 2001).

. "Pobres y criminales. Beneficencia y reforma penitenciaria en el siglo xix en México". Secuencia (27) (1993).

Piña y Palacios, Javier. "El imperio de Maximiliano y las prisiones de México 1864". Criminalia (8) (agosto 1959).

"Las cárceles en 1875". Criminalia (8) (agosto 1959).

SIGÜENZA VIDAL, Fernanda. "La entrada está en tus manos, la salida en las de Dios'. La religión como medio de rehabilitación de los presos en la cárcel de Belén y la penitenciaría de Lecumberri (1874-1900)". Revista de Historia de las Prisiones (2) (2015).

Speckman Guerra, Elisa. "Las flores del mal. Mujeres criminales en el porfiriato". Historia Mexicana 47(1) (1997).

. Crimen y castigo: legislación penal interpretaciones de la criminalidad y administración de justicia (Ciudad de México, 18721910). México: El Colegio de México, 1999.

Trinidad Fernández, Pedro. La defensa de la sociedad: cárcel y delincuencia en España (siglos XVIII-XX). Madrid: Alianza Editorial, 1991.

TRUjILlo BRETón, Jorge. Entre la celda y el muro: rehabilitación social y prácticas carcelarias en la penitenciaría jalisciense "Antonio Escobedo", 1844-1912. México: El Colegio de Michoacán, 2011. 